\title{
Consumer Choice Between Common Generic and Brand Medicines in a Country with a Small Generic Market
}

\author{
Jessica Fraeyman, PhD; Lies Peeters, MSc; Guido Van Hal, PhD; \\ Philippe Beutels, PhD; Guido R.Y. De Meyer, PharmD, PhD; and Hans De Loof, PharmD, PhD
}

\begin{abstract}
BACKGROUND: Generic medicines offer an opportunity for governments to contain pharmaceutical expenditures, since generics are generally $10 \%-80 \%$ lower in price than brand medicines. Belgium has a small generic market that takes up $15 \%$ of the total pharmaceutical market in packages sold.
\end{abstract}

OBJECTIVE: To determine the knowledge of consumers about the different available packages of a common over-the-counter medicine (acetamino-

phen) with regard to price advantage, quality, and effectiveness in a country with a small generic market.

METHODS: We conducted an online survey in the general Flemish population using a questionnaire with 25 statements. The questionnaire also contained 2 informative interventions. First, we showed the price per package and per tablet that the patient would pay in the pharmacy. Second, we provided the respondent with general information about generic medication (equivalence, effectiveness, price, and recognition). Before and after the interventions, we probed for preferences and knowledge about the different packages. Multivariate logistic models were used to examine the independent effects of consumer characteristics on responses to the survey statements.

RESULTS: We obtained a sample of 1,636 respondents. The general attitude towards generic medication was positive-only $5 \%$ would rather not use a generic. Nevertheless, only $17 \%$ of the respondents were able to recognize a generic medicine. Older consumers (aged 60 years and above) were more often confused about the different packages $(\mathrm{OR}=2.59$, $95 \% \mathrm{Cl}=1.76-3.80, P \leq 0.001)$. Consumers without a higher education degree tended to be more doubtful about the difference in effectiveness and quality between the different brands $(\mathrm{OR}=0.59,95 \% \mathrm{Cl}=0.44-0.79$, $P \leq 0.001)$. Consumer recognition of the name of the active substance of acetaminophen was poor. When different brands were displayed, possible price advantage seemed to be an important motive to switch to a cheaper brand. Consumers generally found medicines to be too expensive; however, consumers with medical or paramedical training had a different opinion.

CONCLUSIONS: Two main recommendations can be made to increase the knowledge and enhance the trust in cheaper equivalent medicines. First, highlighting the name of the active substance on the label of medicine packages can reduce confusion and avoid health risks, especially among older consumers. Second, new investments or reallocation of budgets should be considered in order to provide consumers with authoritative information on the bioequivalence and price differences between the different available brands. This would be a cost-effective and potentially costsaving investment for health care payers.

J Manag Care SpecPharm. 2015;21(4):288-96

Copyright $\odot 2015$, Academy of Managed Care Pharmacy. All rights reserved.

\section{What is already known about this subject}

Generic medicines offer an opportunity for governments and consumers to contain pharmaceutical expenditures, since generic prices are generally 10\%-80\% lower than brand medicines.

Consumer acceptance of generic medicines is a prerequisite for acceptance of generic substitution.

Generic substitution can lead to mistakes because of inconsistency in labeling and packaging of pharmaceuticals

\section{What this study adds}

Only $17 \%$ of study respondents were able to recognize a generic medicine package.

About $40 \%$ of respondents failed to differentiate correctly between acetaminophen and acetylsalicylic acid, exposing them to health risks.

Older consumers are more often confused by the differing packaging of generic medicines and would like more identifying labeling. People without a higher education degree have less confidence in the equivalence of different brands.

T n Europe, the generic market share has grown enormously since its introduction. The sales volume varies widely between the different countries but ranges between 10\% and $90 \%$ of the total market. ${ }^{1}$ In Belgium, generics take up approximately $15 \%$ of the total pharmaceutical market share in packages sold. ${ }^{2}$ Generic medicines offer an opportunity for governments and consumers to contain expenditures for pharmaceutical utilization, since generic prices are generally 10\%-80\% lower than their original brand equivalents. ${ }^{3}$ Governments across Europe have implemented a wide range of policy regulations to stimulate generic sales in order to contain growing health care expenditures. ${ }^{1-5}$ The effectiveness of these regulations differs in every country according to the organization of health care insurance. ${ }^{6}$

In today's Western society, the individual behaves as a critical person who no longer accepts the authority of science and medicine at face value. ${ }^{7}$ Also, the pharmaceutical marketing addresses the individual as a consumer of health care who has control over his or her body and health. ${ }^{8}$ Therefore, we refer to the individual in this article as an active "consumer" rather than as a passive "patient." 


\section{FIGURE 1 Five Acetaminophen Packages} Used in Study Questionnaire

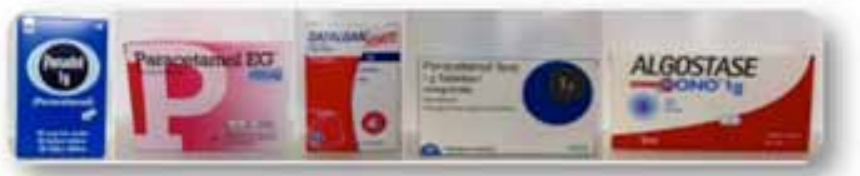

These 5 packages of acetaminophen (known as paracetamol in Europe) were shown to consumers in the online questionnaire used in this study. Dafalgan in the middle is the original brand.

In most cases, over-the-counter (OTC) medication is not reimbursed by Belgian health insurance; therefore, consumers pay full price at the pharmacy. Many studies focus on the use of prescribed generic medication (compared with OTC medication) as an opportunity for health insurance agencies to curb expenditures. ${ }^{9}$ However, our purpose was to study the impact of patients' copayments on their preferred choice of medicine-in this case an OTC medicine. Increasing out-ofpocket cost for prescription medication has been associated with declines in medication adherence and poorer health outcomes. ${ }^{10,11}$ Occasionally, switching to OTC medicines has been shown to reduce overall costs for patients and health plans (e.g., omeprazole). ${ }^{12}$

We list some relevant health-related arguments to study OTC medicine use in the general public. The use of OTC medicines is not without concern; for example, one of the most common medicines worldwide, acetaminophen (often called paracetamol outside of the United States), is responsible for $57 \%$ of acute liver failures in the United Kingdom. ${ }^{13}$ Although patients are in full control of managing self-care medication, they may still need support. Users are more interested in the benefits than the risks of OTC medicines, presuming that only safe medicines are permitted to be sold OTC. ${ }^{7}$ Additionally, consumers seem to have inadequate knowledge about the side effects of OTC medicines. ${ }^{14}$

A number of studies have been done worldwide about consumer views on generic medicines. The acceptance of a generic medicine varies according to the condition for which the medicine is needed. The more serious the condition, the less likely the consumer is willing to accept generic medicine. ${ }^{14-17}$ Health care practitioners are in the position to make consumers more aware of and increase knowledge about generics and medicines in general. ${ }^{4,12,18}$

Consumer acceptance of generic medicines was shown to be a prerequisite for acceptance of generic substitution (that is, the pharmacist switches from a brand prescription to the delivery of a generic medicine). Some might consider generic substitution the ultimate way for increasing generic medicine use and containing pharmaceutical expenditures. ${ }^{19,20}$ However, generic substitution remains highly contested, since many consumers make mistakes with these medications, such as taking the same medicine twice, because of inconsistency in labeling and packaging of the generic pharmaceuticals. ${ }^{20}$ Today's consumerism, however, might be a challenge for pharmacists who seek to develop further their professional role in the surveillance of medicine sales. ${ }^{7}$

We studied the state of knowledge (lay expertise) and perceptions of consumers regarding the OTC medication they buy. What do consumers know about the different available packages of a common medicine (acetaminophen), specifically looking at difference in price, quality, and effectiveness? This study focused on the perceived quality, price, and effectiveness of a number of acetaminophen products with different prices and brand recognition.

\section{Methods}

We conducted an open online survey (www.qualtrics.com) in the general Flemish population using a questionnaire with 25 statements regarding the perception of different brands and packages for a common medicine. We used acetaminophen, a popular OTC medicine, as a case study throughout the questionnaire. In the survey, we showed pictures of 5 different packages of acetaminophen (available at the time in Belgian ambulatory pharmacies; see Figure 1). Respondents were questioned about their knowledge; perception of quality, effectiveness, and price; preference; and utilization of this particular medicine and generic medicines in general. The design of the questionnaire was inspired by other studies after a literature review.

The questionnaire was distributed through several different channels: Internet forums, company mailing lists, newsletters of popular science magazines, and social media (Facebook wall). The statements were evaluated with a Likert-type scale from 1 to 5, ranging from "completely don't agree" to "completely agree."

The questionnaire contained 2 informative interventions. First, we showed the price that the patient would pay in the pharmacy per package and per tablet. Second, we provided the respondent with general information about generic medicines (equivalence, effectiveness, price, and recognition). Changes in knowledge and preferences before and after these interventions are discussed in the Results section.

Multivariate logistic models were used to examine the independent effects of consumer characteristics on statements regarding generic medicines and consumer perceptions on the different available packages for a common OTC medicine. Odds ratios (OR) were calculated (adjusted for gender, age, level of education, and medical or paramedical training), and 95\% confidence intervals (CI) were provided to demonstrate the risk estimate. We considered significance when $P$ values were below 0.05. All analyses were performed in SPSS 22.0 (SPSS, Inc., Chicago, IL). 


\section{Results}

In April 2013, we collected 1,636 questionnaires from Flanders, the Dutch-speaking region in Belgium. The sample had a slight overrepresentation of young, female, and higher educated respondents. One-fourth of the sample enjoyed medical or paramedical training (based on self-report). To examine the independent effect of these characteristics, we corrected for gender, age, and level of education in the logistic model.

In Belgium, the following are acknowledged as paramedical professions: pharmaceutical-technical assistants, dieticians, occupational therapists, speech therapists, audiologists and hearing-aid specialists, orthoptists, medical laboratory technologists, medical imaging technologists, bandagists, orthotists, prosthetists, podiatrists, and patient transport service drivers.

When the respondents were asked to select actual brand names for acetaminophen, $45.9 \%$ could select none. When asked to select the main indication for acetaminophen, 86.6\% of respondents selected the correct option. Hence, consumers knew more about the indication rather than the name of the medicine (see Table 1).

About half of the sample had used a prescription medicine $(48.3 \%, \mathrm{n}=790)$ or an OTC medicine $(46.3 \%, \mathrm{n}=758)$ in the 2 weeks preceding the questionnaire. A smaller proportion of respondents used a generic medicine $(35.7 \%, \mathrm{n}=584)$ during that period, and $9.0 \%$ of the respondents did not know whether or not they had used a generic $(n=148$; Table 1$)$.

Only 5.4\% ( $\mathrm{n}=89)$ would rather not have used a generic medicine. Remarkably, half of the respondents $(51.8 \%, \mathrm{n}=848)$ were not able to recognize a generic medicine. An even larger proportion $(60.6 \%, \mathrm{n}=992)$ agreed about the necessity to add information on the medicine package concerning the status of the medicine (generic or not). Despite relative high utilization of generic medicines and general positive attitudes towards these medicines, 1 in 2 respondents could not recognize a generic medicine package (Figure 2).

More than half of the respondents $(57.6 \%, \mathrm{n}=942)$ believed that the different brands have an equal effect; $13.8 \%$ of the respondents ( $n=226)$ did not agree; and $23.8 \%$ of the respondents $(n=389)$ were neutral. One-third $(34 \%, n=351)$ of the respondents believed that there is a difference in side effects, and $40 \%(n=650)$ of the respondents were neutral. There is a sharp contrast between the scepticism of consumers about the equivalence in effectiveness and the scientific consensus about the bioequivalence of these products (Figure 1).

When viewing the different packages, respondents gave their preferences and reasons for choosing a certain package. After the first intervention, where the price per package and tablet were shown, respondents again selected their package of preference (Figure 3). At this point, the brand Dafalgan was the most preferred package (52\%) and also the most

\section{TABLE 1 Characteristics of the Sample}

\begin{tabular}{|c|c|c|}
\hline Survey Participant Characteristics & $\%$ & $\mathbf{n}$ \\
\hline \multicolumn{3}{|l|}{ Gender } \\
\hline Male & 36.3 & 594 \\
\hline Female & 63.7 & 1,042 \\
\hline \multicolumn{3}{|l|}{ Age } \\
\hline $18-29$ & 36.4 & 595 \\
\hline $30-44$ & 16.6 & 272 \\
\hline $45-59$ & 27.8 & 454 \\
\hline $60-79$ & 18.4 & 301 \\
\hline $80+$ & 0.9 & 14 \\
\hline \multicolumn{3}{|c|}{ Are you medically or paramedically trained? } \\
\hline Yes & 23.4 & 383 \\
\hline No & 76.6 & 1,253 \\
\hline \multicolumn{3}{|l|}{ Level of education (highest degree) } \\
\hline None/primary school & 2.0 & 32 \\
\hline Lower secondary school & 7.5 & 122 \\
\hline Higher secondary school & 34.8 & 569 \\
\hline Higher education & 55.8 & 913 \\
\hline \multicolumn{3}{|c|}{ Use of prescribed medicines in the past 2 weeks? } \\
\hline Yes & 48.3 & 790 \\
\hline No & 44.3 & 725 \\
\hline I don't know & 0.1 & 2 \\
\hline Missing & 7.3 & 119 \\
\hline \multicolumn{3}{|c|}{ Use of over-the-counter medicines in the past 2 weeks? } \\
\hline Yes & 46.3 & 758 \\
\hline No & 45.7 & 747 \\
\hline I don't know & 0.7 & 12 \\
\hline Missing & 7.3 & 119 \\
\hline \multicolumn{3}{|c|}{ Use of generic medicines in the past 2 weeks? } \\
\hline Yes & 35.7 & 584 \\
\hline No & 48.0 & 785 \\
\hline I don't know & 9.0 & 148 \\
\hline Missing & 7.3 & 119 \\
\hline \multicolumn{3}{|c|}{ Select the possible brand names for acetaminophen ${ }^{a}$} \\
\hline Aspirin & 21.1 & 341 \\
\hline Ibuprofen & 11.6 & 188 \\
\hline Panadolb & 20.2 & 327 \\
\hline Dafalgan $^{\mathrm{b}}$ & 65.3 & 1,056 \\
\hline Nurofen & 13.2 & 214 \\
\hline Algostase Mono ${ }^{\mathrm{b}}$ & 6.9 & 111 \\
\hline I don't know & 18.3 & 296 \\
\hline \multicolumn{3}{|c|}{ Select the right indication for acetaminophen ${ }^{a}$} \\
\hline Pain and fever & 90.5 & 1,463 \\
\hline Nausea and vomiting & 1.7 & 28 \\
\hline Diarrhea & 0.1 & 1 \\
\hline Cough & 0.6 & 9 \\
\hline I don't know & 8.9 & 144 \\
\hline
\end{tabular}

aRespondents were allowed to select multiple options.

bAcetaminophen is marketed in Belgium under the following brand names: Panadol, Dafalgan, and Algostase Mono.

expensive one. After receiving the price information, only $27 \%$ preferred Dafalgan. A large proportion of respondents shifted their preference to 1 of the less expensive alternatives: Paracetamol EG (42\%) or Algostase Mono (24\%). Regarding the 


\section{FIGURE 2 Consumer Response to 5 Statements Regarding Effectiveness of Different} Packaging of Acetaminophen and Generic Medicines

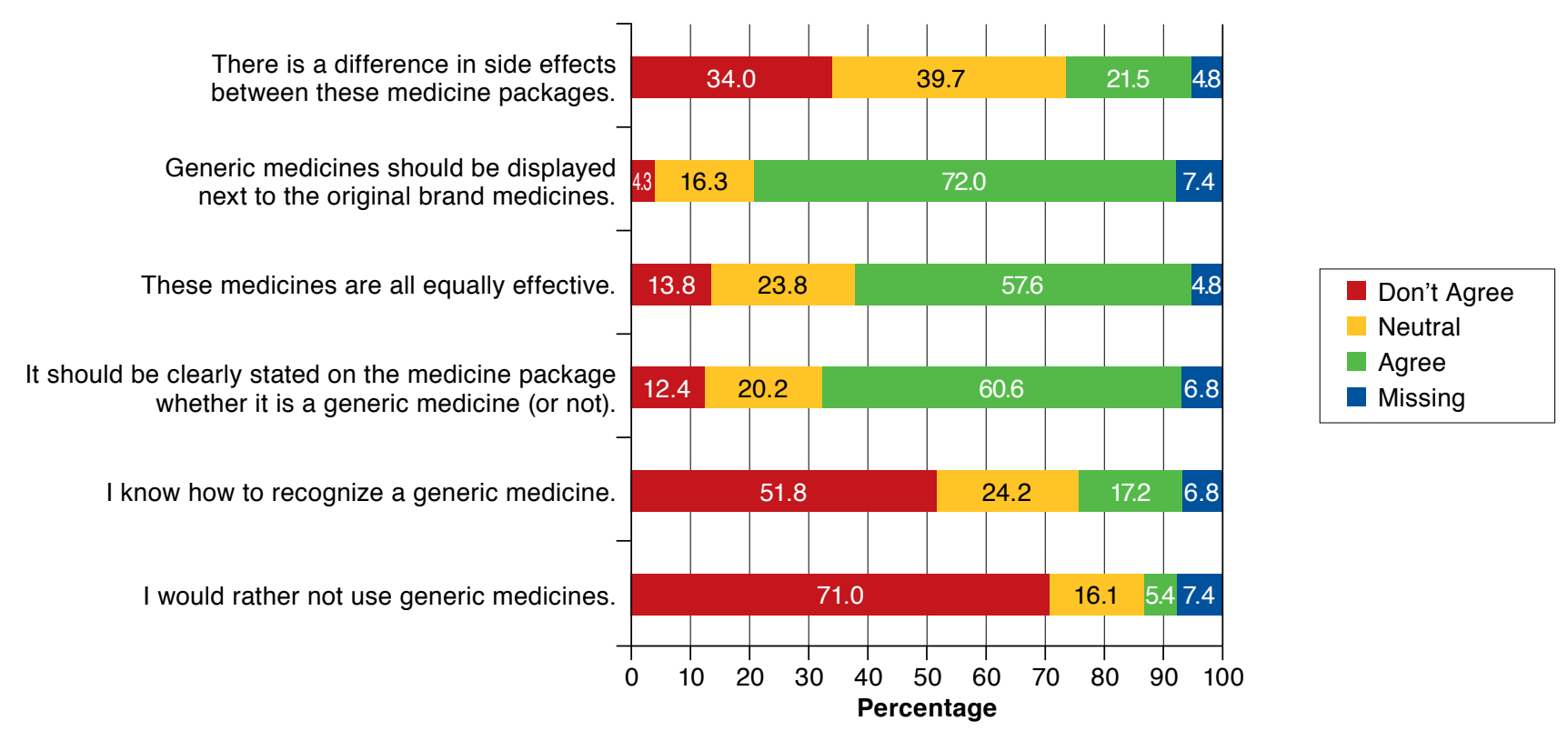

motivationforchoosing a particularpackage, aboutone-third of the respondents (36\%) indicated that they chose a cheaper package because of its lower price, whereas another third (33\%) indicated that they preferred to stick with their original package choice (regardless of its price) because they were familiar with it. The remaining $31 \%$ gave a variety of other reasons for choosing their packages (e.g., advice from physician or appearance of the package).

\section{Logistics Model}

Older and lower-educated consumers found medicines in general to be too expensive, but medically and paramedically trained consumers did not. Although lower-educated consumers considered medicines to be too expensive, they tended to be more brand loyal regardless of the price change $(\mathrm{OR}=1.54$, 95\% CI = 1.23-1.94, P $\leq$ 0.001; Table 2).

Older consumers mostly looked for information and clarification regarding the different available packages because they tended to be more confused about the different packages than younger consumers $(\mathrm{OR}=2.59,95 \% \mathrm{CI}=1.76-3.80$, $P \leq 0.001)$. They tended to be more brand loyal to avoid confusion $(\mathrm{OR}=1.33,95 \% \mathrm{CI}=0.99-1.78, P=0.055)$. Therefore, they recommended that labels be added to medicine packages if they were generic medicine $(\mathrm{OR}=2.81,95 \% \mathrm{CI}=1.68-4.70$, $P \leq 0.001)$. Although they would ask their physicians or pharmacists for more information regarding generic medicines, they preferred to look for information themselves $(O R=3.62,95 \%$ $\mathrm{CI}=2.46-5.33, P \leq 0.001)$.
The need for information seemed to be different for male and female consumers. Men found information regarding the price essential to make a choice between packages $(\mathrm{OR}=1.31$, 95\% CI $=1.01-1.70, P=0.041)$ and also needed less assurance concerning quality and effectiveness $(\mathrm{OR}=0.35,95 \% \mathrm{CI}=0.18$ $0.68, P=0.002$ )

The group of lower-educated consumers seemed to be explicitly more concerned about the difference in side effects $(\mathrm{OR}=1.75,95 \% \mathrm{CI}=1.32-2.32, P \leq 0.001)$ and had less confidence in the effectiveness ( $\mathrm{OR}=0.59,95 \% \mathrm{CI}=0.44-0.79$, $P \leq 0.001)$ and quality difference between the different brands $(\mathrm{OR}=0.56,95 \% \mathrm{CI}=0.42-0.75, P \leq 0.001)$.

In general, consumers with medical or paramedical training had distinctly different opinions about the different packages. They considered the different medicine packages to be equally effective and to be of equal quality. Remarkably, they were not in favor of adding information about the indication on the medicine package $(\mathrm{OR}=0.37,95 \% \mathrm{CI}=0.19-0.72, \mathrm{P}=0.003)$.

\section{Discussion}

This study provides insight into the knowledge and perceptions of the general Flemish population regarding the different available packages of a common OTC medicine in a country with a small generic market.

The general attitude towards generic medication was positive; only $5 \%$ of respondents indicated that they would rather not use a generic. Nevertheless, only $17 \%$ were able to 

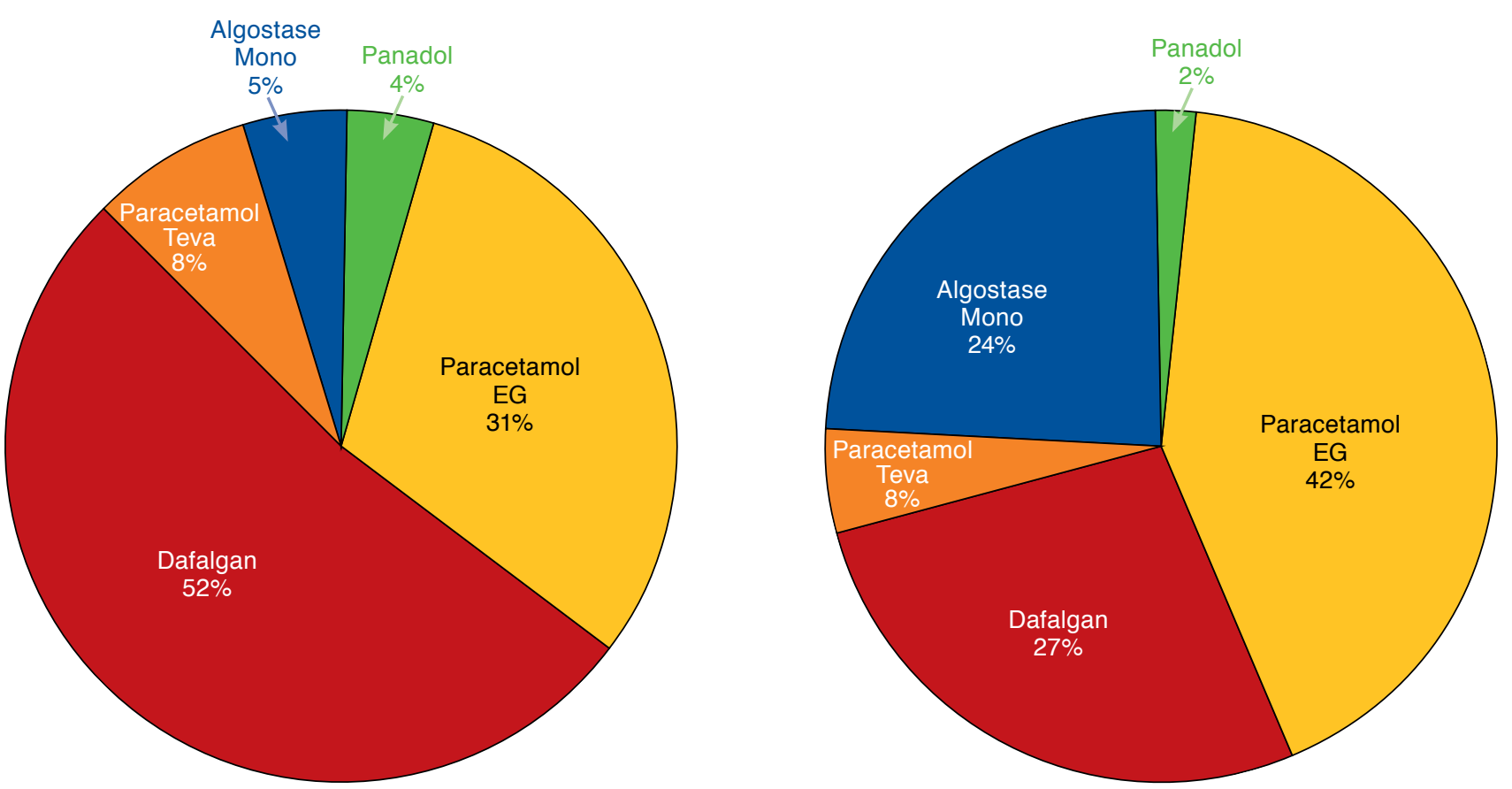

aThis figure shows preferred packaging of acetaminophen (1 gram, 50-60 tablets) before (left panel) and after (right panel) survey respondents received information on the price per package and tablet.

recognize a generic medicine package. When viewing the different available packages of a common OTC medicine, the majority of respondents believed that they were not equally effective. Also, uncertainty arose about the difference in side effects between brands, especially among lower-educated consumers.

When consumers were informed about the prices of the different packages, we saw a large shift in preference from the more expensive original brand medicine to the cheaper (generic) alternatives. However, one-third of consumers remained loyal to their brands, regardless of the price. This brand loyalty occurred especially in lower-educated consumers, mainly because they believed that effectiveness and quality differ between brands. Older consumers also seemed to be loyal to their brands, mainly to avoid confusion between the different packages. They were actively looking for more information regarding the different generic medicine options. They firmly believed that it should be clearly stated on the medicine package whether it is a generic medicine or not.

Aside from a small Flemish study in 2002, ${ }^{21}$ no results have been published concerning consumer attitude and knowledge regarding common OTC medicines in Belgium. Although many policy regulations have been put in place in Belgium during the past 15 years, these mainly seem to target physicians and pharmacists. ${ }^{2,4}$ Few resources are invested in patient education. However, this seems to be an area of great opportunity. Studies have shown that health literacy in patients can be increased through patient education and empowerment. ${ }^{22,23}$ Comparable results were found in Spain, another country with a small generic market. ${ }^{24}$ In the current study, we see opportunity for educating consumers about the equivalence of generic versus original brand medicines, especially in older and lowereducated consumers. Educational outreach could enhance consumer knowledge and also empower consumers to better manage their medicine use.

Many of our results are similar to those from previous studies. The primary reason for consumers to choose a generic medicine seems to be price advantage, 9,25,26 although generic medicines may also be perceived as lower in quality due to the lower price. ${ }^{27}$ Our study showed that besides familiarity, the price advantage seemed to be the most important motive to switch between packages. Although health professionals (including paramedics) may have different perceptions about this, the price of the medicine might be an important topic to discuss with consumers during consultations.

The difference in side effects remains a concern for consumers, as was also seen in an earlier study by Al-Gedadi et 
TABLE 2 Consumer Evaluation of Statements Regarding Different Packages of a Common Medication ${ }^{a}$

\begin{tabular}{|c|c|c|c|c|}
\hline \multirow[b]{2}{*}{ Reference Category } & Gender & Age & Education & $\begin{array}{c}\text { Medical or } \\
\text { Paramedical Training }\end{array}$ \\
\hline & Reference: Female & Reference: Aged $<60$ years & $\begin{array}{l}\text { Reference: Obtained a degree } \\
\text { for higher education, } \\
\text { university, or higher }\end{array}$ & $\begin{array}{l}\text { Reference: Not medically or } \\
\text { paramedically trained } \\
\quad \text { (self-reported) }\end{array}$ \\
\hline \multicolumn{5}{|c|}{ In general, I consider medicines to be too expensive } \\
\hline Adjusted OR & $0.98(0.71-1.34)$ & $2.09(1.37-3.17)^{b}$ & $1.42(1.05-1.93) P=0.021$ & $0.57(0.41-0.80)^{b}$ \\
\hline \multicolumn{5}{|c|}{ These medicines are equally effective } \\
\hline Adjusted OR & $1.48(1.07-2.05) P=0.018$ & $0.75(0.51-1.10)$ & $0.59(0.44-0.79)^{b}$ & $1.87(1.28-2.74)^{b}$ \\
\hline \multicolumn{5}{|c|}{ There is a difference in side effects between these medicines } \\
\hline Adjusted OR & $0.81(0.60-1.08)$ & $1.22(0.84-1.78)$ & $1.75(1.32-2.32)^{b}$ & $0.70(0.51-0.96) P=0.03$ \\
\hline \multicolumn{5}{|c|}{ The quality of these medicines is equal } \\
\hline Adjusted OR & $1.46(1.07-2.01) P=0.018$ & $0.70(0.48-1.01) P=0.055$ & $0.56(0.42-0.75)^{b}$ & $1.52(1.06-2.19) P=0.022$ \\
\hline \multicolumn{5}{|c|}{ I choose the same product every time because it is familiar to me, regardless of the price } \\
\hline Adjusted OR & $0.79(0.62-1.01) P=0.055$ & $1.20(0.90-1.61)$ & $1.54(1.23-1.94)^{b}$ & $0.89(0.68-1.17)$ \\
\hline \multicolumn{5}{|c|}{ In order to avoid confusion, I choose the same package every time } \\
\hline Adjusted OR & $0.97(0.76-1.24)$ & $1.33(0.99-1.78) P=0.055$ & $1.17(0.93-1.47)$ & $0.64(0.49-1.85) P=0.002$ \\
\hline \multicolumn{5}{|c|}{ I believe a cheaper medicine is of lower quality } \\
\hline Adjusted OR & $0.86(0.60-1.25)$ & $0.76(0.48-1.22)$ & $1.38(0.98-1.96)$ & $0.31(0.18-0.54)^{b}$ \\
\hline \multicolumn{5}{|c|}{ I find the information about price essential to make a good choice } \\
\hline Adjusted OR & $1.31(1.01-1.70) P=0.041$ & $1.32(0.95-1.84)$ & $0.85(0.66-1.09)$ & $1.45(1.07-1.96) P=0.016$ \\
\hline \multicolumn{5}{|c|}{ I find the information about effectiveness essential to make a good choice } \\
\hline Adjusted OR & $0.38(0.19-0.76) P=0.006$ & $0.48(0.24-0.98)$ & $1.15(0.58-2.27)$ & $0.50(0.24-1.04)$ \\
\hline \multicolumn{5}{|c|}{ I find the information about quality essential to make a good choice } \\
\hline Adjusted OR & $0.35(0.18-0.68) P=0.002$ & $0.61(0.30-1.23)$ & $1.07(0.56-2.05)$ & $0.55(0.27-1.14)$ \\
\hline \multicolumn{5}{|c|}{ It should be clearly stated on the medicine package whether it concerns a generic medicine (or not) } \\
\hline Adjusted OR & $1.03(0.74-1.44)$ & $2.81(1.68-4.70)^{b}$ & $1.34(0.97-1.86)$ & $0.71(0.51-1.02)$ \\
\hline \multicolumn{5}{|c|}{ I find the different packages confusing } \\
\hline Adjusted OR & $1.14(0.87-1.51)$ & $2.59(1.76-3.80)^{b}$ & $0.93(0.72-1.20)$ & $0.64(0.48-0.85) P=0.002$ \\
\hline \multicolumn{5}{|c|}{ It should be clearly stated on the package itself what the medicine is used for } \\
\hline Adjusted OR & $0.79(0.39-1.57)$ & $1.49(0.57-3.92)$ & $1.40(0.71-2.79)$ & $0.37(0.19-0.72) P=0.003$ \\
\hline \multicolumn{5}{|c|}{ I would prefer to know for which medicines there exists a generic equivalent } \\
\hline Adjusted OR & $0.87(0.54-1.41)$ & $4.67(1.85-11.80)^{b}$ & $0.60(0.38-0.94) P=0.024$ & $1.12(0.64-1.95)$ \\
\hline \multicolumn{5}{|c|}{ Next time I will ask my pharmacist for a generic medicine } \\
\hline Adjusted OR & $0.86(0.62-1.19)$ & $1.69(1.12-2.56) P=0.013$ & $0.75(0.56-1.03)$ & $0.95(0.66-1.37)$ \\
\hline \multicolumn{5}{|c|}{ Next time I will ask my physician for a generic medicine } \\
\hline Adjusted OR & $1.15(0.83-1.60)$ & $2.13(1.36-3.32)^{b}$ & $0.81(0.59-1.10)$ & $0.93(0.64-1.34)$ \\
\hline \multicolumn{5}{|c|}{ Next time I will look for information myself } \\
\hline Adjusted OR & $0.91(0.67-1.22)$ & $3.62(2.46-5.33)^{b}$ & $1.21(0.91-1.61)$ & $1.19(0.84-1.66)$ \\
\hline \multicolumn{5}{|c|}{$\begin{array}{l}\text { Note: Data are presented as OR }(95 \% \mathrm{CI}) \text { and } P \text { values (Walch chi-square test). Only ORs after adjustment are shown here. } \\
\text { ac Complete case analyses before and after adjustment for gender, age, level of education, and self-reporting of medical or paramedical training }(N=1,636) \text {. } \\
\text { bP } P \leq .001 \text {. } \\
C I=\text { confidence interval; } O R=\text { odds ratio. }\end{array}$} \\
\hline
\end{tabular}

al. (2008). ${ }^{28}$ When consumers believe that the effectiveness of generic medicines is less than their original brand equivalents, they are less likely to accept generic medicines or generic substitution..$^{19,27,29}$ Additionally, older consumers and those with lower levels of education are less likely to accept generic substitution. ${ }^{30,31}$ This seems to be no different in other countries with a small generic market share, such as Portugal. ${ }^{17}$

Acceptance of generic medicines (and generic substitution) seems no different between countries with small generic mar- kets (Spain, Portugal, and Belgium) and countries with large generic markets (Germany, Norway, and Finland). ${ }^{17,24,25,27,32}$ The factors that influence the evolution of generic market share are diverse and country specific. In that regard, we cannot ignore the large influence of original brand-producing companies on the evolution of Belgian pharmaceutical sales.

Insurance coverage was shown to be an important factor in acceptance of generic substitution by consumers. ${ }^{30,31}$ This, however, does not apply to Belgium, where basic health 
insurance coverage is available to everyone, although this coverage does not include OTC medicines.

Lay expertise is becoming recognized as a determinant of medicine consumption in health care research; however, the content of this expertise is variable. , $^{733,34}$ The role of lay expertise becomes even more prominent for OTC medicines, since professional surveillance is often lacking. The survey used in this study found that patients are more aware of the symptoms that acetaminophen alleviates than they are of acetaminophen's differing brand names. Half of the respondents in the current study did not know any of the brand names under which acetaminophen is sold. These results are similar to previous results from the United Kingdom. ${ }^{35}$ This lack of knowledge about differing brand names may lead to serious health risks because of such errors as taking the wrong medication or combining products that might result in toxic doses. ${ }^{20,36}$ We suggest an important adjustment to current pharmaceutical labeling. The name of the active substance (INN) should be added to the label in the same font size as the brand name to increase recognition of the medicine. This can reduce confusion, especially in the older population, ${ }^{37}$ and it can avoid considerable costs for the health care payer. Additionally, this may increase the acceptance of compulsory generic substitution, ${ }^{20}$ which has only recently been implemented in Belgium.

Variety in medicine package labeling seems to be part of the European reality. Whereas in some other European countries and in the United States a selection of a common medication (e.g., acetaminophen) can be bought in general retail (e.g., at the grocery store or supermarket), in Belgium the pharmacist and physician remain important in guiding OTC medicine consumption. As first contact person for the consumer, the pharmacist has the responsibility to supervise the use of medication, which includes addressing any concerns of consumers regarding packaging or labeling. Hence, in anticipation of changes in labeling for medicine packages, the importance of pharmaceutical care in OTC medicine use needs to be kept in mind. Multiple studies have shown that medication reviews (which could include addressing confusion about medicine labels) by the pharmacist improve the clinical outcomes in patients. ${ }^{38}$

Pharmaceutical care as a fairly new practice is still gaining acceptance as an integral part of health care. Lay expertise may influence this development as consumers continue to gain more knowledge through other nonprofessional sources. ${ }^{7,8}$ This study documents the status of lay expertise on a common OTC medicine, which can help shape the role of the pharmacist as a gatekeeper for medicine purchase. From our study, it is clear that consumers have a knowledge deficit about common OTC medicines. This highlights the need for effective professional supervision of all OTC medicine delivery in managed care pharmacy or a pharmacy where a pharmacist is always present, as is the case in Belgium but not always the case elsewhere.

\section{Limitations}

Although there may be an association between level of education and level of income, the lack of data on household income might be considered as a lost opportunity in this study. Also, we do not have any data that could give us more information on the literacy of the sample.

The reported medicine use was limited to "the past 2 weeks," and it was not specified whether it concerned acetaminophen. Including an "ever used" question would have added interesting information to the dataset. However, since recall bias can distort the accuracy of self-reported data, respondents might find it easier to recall their medicine use of the previous 2 weeks rather than from a longer time span.

\section{Conclusions}

Although there seems to be a general positive attitude towards generic medicines, there remains distrust in relation to effectiveness between different (and cheaper) brands of a common OTC medicine, especially among lower-educated consumers. Two main recommendations can be made to increase knowledge and enhance trust in cheaper equivalent medicines. First, highlighting the name of the active substance on the label of medicine packages can reduce confusion and avoid health risks, especially among older consumers. Second, new investments or reallocation of budgets should be considered in order to provide consumers with authoritative information on the bioequivalence and price differences between the different available brands of OTC and prescribed medication. This recommendation would be a cost-effective and potentially costsaving investment for health care payers (patients and national health insurance).

\section{Authors}

JESSICA FRAEYMAN, PhD, is Senior Researcher, and GUIDO VAN HAL, PhD, is Professor, Department of Epidemiology and Social Medicine, Research Unit of Medical Sociology and Health Policy, University of Antwerp, Belgium. LIES PEETERS, MSc, is Community Pharmacist, Antwerp, Belgium. PHILIPPE BEUTELS, $P h D$, is Professor, Centre for Health Economics Research and Modeling Infectious Diseases (CHERMID), Vaccine and Infectious Disease Institute (VAXINFECTIO), and GUIDO R.Y. DE MEYER, PharmD, PhD, is Professor, Department of Physiopharmacology, University of Antwerp. HANS DE LOOF, PharmD, PhD, is PartTime Lecturer, Department of Physiopharmacology, University of Antwerp, and Community Pharmacist, Bruges, Belgium.

AUTHOR CORRESPONDENCE: Jessica Fraeyman, PhD, University of Antwerp, Universiteitsplein 1, 2610 Wilrijk (Antwerp), Belgium. Tel.: +32.3.265.28.55; Fax: +32.3.265.28.75;

E-mail: jessica.fraeyman@uantwerpen.be. 


\section{DISCLOSURES}

Grants from the Special Research Fund [Bijzonder Onderzoeksfonds (BOF)] of the University of Antwerp funded this research through an InterDisciplinary Doctoral scholarship (ID).

Study concept and design were contributed by Peeters and Fraeyman, with assistance from De Loof. Peeters and Fraeyman collected the data, assisted by De Loof. Data were interpreted primarily by Fraeyman, along with Peeters and assisted by De Loof. The manuscript was written by Fraeyman and De Loof, with the assistance of the other authors. Van Hal, Beutels, and De Meyer were primarily responsible for revising the manuscript, with assistance from Fraeyman, De Loof, and Peeters.

\section{ACKNOWLEDGMENTS}

We would like to acknowledge Anne-Marie Lambeir from the Department of Pharmaceutical Sciences at the University of Antwerp for her guidance in data collection and data analysis during the early stages of this study.

\section{REFERENCES}

1. Dylst P, Simoens S. Generic medicine pricing policies in Europe: current status and impact. Pharmaceuticals. 2010;3(3):471-81.

2. Fraeyman J, Van Hal G, De Loof H, Remmen R, De Meyer GR, Beutels P. Potential impact of policy regulation and generic competition on sales of cholesterol lowering medication, antidepressants and acid blocking agents in Belgium. Acta Clinica Belg. 2012;67(3):160-71.

3. Dylst P, Vulto A, Simoens S. Demand-side policies to encourage the use of generic medicines: an overview. Expert Rev Pharmacoecon Outcomes Res. 2013;13(1):59-72

4. Fraeyman J, Godman B, Van Hal G, Beutels P. The potential influence of various initiatives to improve rational prescribing for proton pump inhibitors and statins in Belgium. Expert Rev Pharmacoecon Outcomes Res. 2012;13(1):141-51.

5. Godman B, Shrank W, Andersen M, et al. Policies to enhance prescribing efficiency in Europe: findings and future implications. Front Pharmacol. 2010;1:141

6. Dylst P, Vulto A, Simoens S. Overcoming challenges in market access of generic medicines in the European Union. J Generic Med. 2012;9(21):21-28.

7. Hibbert D, Bissell P, Ward PR. Consumerism and professional work in the community pharmacy. Sociol Health Ill. 2002;24(1):46-65.

8. Williams SJ, Calnan M. The 'limits' of medicalization? Modern medicine and the lay populace in 'late' modernity. Soc Sci Med. 1996;42(12):1609-20.

9. Hassali MA, Shafie AA, Jamshed S, Ibrahim MI, Awaisu A. Consumers' views on generic medicines: a review of the literature. Int J Pharm Pract. 2009;17(2):79-88.

10. Clark B, Duchane J, Hou J, Rubinstein E, McMurray J, Duncan I. Evaluation of increased adherence and cost savings of an employer valuebased benefits program targeting generic antihyperlipidemic and antidiabetic medications. J Manag Care Spec Pharm. 2014:20(2):141-50. Available at: http://www.amcp.org/WorkArea/DownloadAsset.aspx?id=17578.

11. Eaddy MT, Cook CL, O’Day K, Burch SP, Cantrell CR. How patient cost-sharing trends affect adherence and outcomes: a literature review. PT. 2012:37(1):45-55

12. Harris BN, West DS, Johnson J, Hong SH, Stowe CD. Effects on the cost and utilization of proton pump inhibitors from adding over-the-counter omeprazole to drug benefit coverage in a state employee health plan.

J Manag Care Spec Pharm. 2004;10(5):449-55. Available at: http://www.amcp. org/data/jmcp/Contemporary\%20Subject-449-455.pdf.

13. Bernal W, Wendon J. Acute liver failure. N Engl J Med. 2013;369(26): 2525-34.
14. Hughes L, Whittlesea C, Luscombe D. Patients' knowledge and perceptions of the side-effects of OTC medication. J Clin Pharm Ther. 2002;27(4):243-48.

15. Ganther JM, Kreling DH. Consumer perceptions of risk and required cost savings for generic prescription drugs. J Am Pharm Assoc (Wash). 2000;40(3):378-83.

16. Sewell K, Andreae S, Luke E, Safford MM. Perceptions of and barriers to use of generic medications in a rural African American population, Alabama, 2011. Prev Chronic Dis. 2012;9:E142.

17. Figueiras MJ, Marcelino D, Cortes MA. People's views on the level of agreement of generic medicines for different illnesses. Pharm World Sci. 2008;30(5):590-94.

18. European Commission. Report of the working group on promoting good governance of non-prescription drugs in Europe. June 2013. Available at: http://ec.europa.eu/enterprise/sectors/healthcare/files/docs/otc_report_ en.pdf. Accessed January 17, 2015.

19. Shrank WH, Cadarette SM, Cox E, et al. Is there a relationship between patient beliefs or communication about generic drugs and medication utilization? Med Care. 2009:47(3):319-25.

20. Emery J, McKenzie A, Bulsara C, Holman D. Controversy over generic substitution. BMJ. 2010;341:c3570.

21. Van Hal G, Reel V, Totté J, Meheus A. The prescription of generic drugs. A survey of general practitioners in the Antwerp region (Flanders, Belgium). Tijdschrift voor Geneeskunde. 2002;58(1):2-13.

22. Ciciriello S, Johnston RV, Osborne RH, et al. Multimedia educational interventions for consumers about prescribed and over-the-counter medications. Cochrane Database Syst Rev. 2013;4:CD008416.

23. Hassali MA, Kong DC, Stewart K. Generic medicines: perceptions of consumers in Melbourne, Australia. Int J Pharm Pract. 2005;13(4):257-64

24. Vallès JA, Barreiro M, Cereza G, et al. A prospective multicenter study of the effect of patient education on acceptability of generic prescribing in general practice. Health Policy. 2003;65(3):269-75.

25. Heikkilä R, Mäntyselkä P, Ahonen R. Do people regard cheaper medicines effective? Population survey on public opinion of generic substitution in Finland. Pharmacoepidemiol Drug Saf. 2011;20(2):185-91.

26. Bearden WO, Mason JB. Consumer-perceived risk and attitudes toward generically prescribed drugs. J Appl Psychol. 1978;63(6):741-46.

27. Himmel W, Simmenroth-Nayda A, Niebling W, et al. What do primary care patients think about generic drugs? Int J Clin Pharmacol Ther 2005;43(10):472-79

28. Al-Gedadi NA, Hassali MA, Shafie AA. A pilot survey on perceptions and knowledge of generic medicines among consumers in Penang, Malaysia. Pharm Pract (Granada). 2008;6(2):93-97.

29. Lambert ZV, Doering PL, Goldstein E, McCormick WC. Predispositions toward generic drugs acceptance. J Consum Res. 1980;7(1):14-23.

30. Kendall K, Simon N, Schoner B. Consumer response to generic/chemically equivalent drugs. J Public Policy Mark. 1991;10(2):182-201.

31. Iosifescu A, Halm EA, McGinn T, Siu AL, Federman AD. Beliefs about generic drugs among elderly adults in hospital-based primary care practices. Patient Educ Couns. 2008;73(2):377-83.

32. Kjoenniksen I, Lindbaek M, Granas AG. Patients' attitudes towards and experiences of generic drug substitution in Norway. Pharm World Sci. 2006;28(5):284-89.

33. Popay J, Williams G. Public health research and lay knowledge. Soc Sci Med. 1996;42(5):759-68.

34. Figueiras MJ, Cortes MA, Marcelino D, Weinman J. Lay views about medicines: the influence of the illness label for the use of generic versus brand. Psychol Health. 2010;25(9):1121-28. 
35. Wood DM, English E, Butt S, Ovaska H, Garnham F, Dargan PI. Patient knowledge of the paracetamol content of over-the-counter (OTC) analgesics, cough/cold remedies and prescription medications. Emerg Med J. 2010;27(11):829-33.

36. Bulsara C, McKenzie A, Sanfilippo F, Holman CD, Emery JE. 'Not the full Monty': a qualitative study of seniors' perceptions of generic medicines in Western Australia. Aust J Prim Health. 2010;16(3):240-45.
37. Kairuz T, Bye L, Birdsall R, et al. Identifying compliance issues with prescription medicines among older people: a pilot study. Drugs Aging. 2008;25(2):153-62.

38. Nkansah N, Mostovetsky O, Yu C, et al. Effect of outpatient pharmacists' non-dispensing roles on patient outcomes and prescribing patterns. Cochrane Database Syst Rev. 2010(7):CD000336. 